\title{
STUDI PEMETAAN PERILAKU (BEHAVIORAL MAPPING) PEJALAN KAKI PADA PEDESTRIAN ALUN-ALUN KOTA LAMONGAN
}

\author{
Hammam Rofiqi Agustapraja
}

Dosen Fakultas Teknik Prodi Teknik Sipil Universitas Islam Lamongan

email: hammam.ra@gmail.com

\begin{abstract}
Aloon-aloon of Lamongan area is the area that became the center of the crowd in Lamongan. This area is very strategic because it can be reached by all walks of life from various parts of the city. Pedestrian in Aloon-aloon of Lamongan experienced a change of function at night that is as a center of street hawkers, thus making pedestrian rights become reduced. The existence of various kinds of problems make the function of the pedestrian and the convenience of pedestrian activity is not running properly. from this research is to know the pattern of pedestrian behavior in Area of Aloon-Aloon of Lamongan based on existing rules and regulations. Data analysis uses qualitative analysis which is used to explain the result of survey which conducted in Area of Aloon-aloon of Lamongan about public response to pedestrian. The results of this study are expected to provide future input on the development of pedestrian both in terms of function and comfort so that the pedestrian line functions properly as an open space that should be used for pedestrian activity so that the creation of comfort for users, and impact on the image of a pedestrian-friendly City.
\end{abstract}

Keywords: Pedestrian, Function, Convenience

\section{PENDAHULUAN}

Ruang publik adalah ruang luar yang digunakan untuk kegiatan penduduk kota sehari-hari. Menurut Hakim (1987) dalam Listianto (2006), fungsi ruang publik bagi pejalan kaki antara lain untuk bergerak dari satu bangunan ke bangunan yang lain, dari banguanan ke open space yang ada atau sebaliknya, atau dari satu tempat ke tempat yang lainnya di sudut kawasan ruang publik.

Menurut Yeang (1986) dalam Listianto (2006), ruang terbuka kota berfungsi sebagai tempat aktivitas manusia, sebagai ruang transisi untuk bergerak dari bangunan satu kebangunan yang lain atau dari satu tempat ke tempat yang lain. Ruang terbuka kota juga berfungsi sebagai tempat interaksi social masyarakat kota dan lain-lain. Interaksi ini tidak dapat terjadi pada orang-orang yang berada di dalam kendaraan bermotor tetapi pada pejalan kaki. Denyut kehidupan kota dan vitalitas kota terlihat dari adanya aktifitas pejalan kaki di ruang kota.

Berjalan kaki merupakan bagian dari system transportasi atau system penghubung kota (linkage system) yang cukup penting.
Karena dengan berjalan kaki dapat dapat mencapai semua sudut kota yang tidak dapat ditempuh dengan kendaraan bermotor.

Menurut Sirvani (1985), jalur pejalan kaki merupakan elemen penting perancangan kota. Ruang pejalan kaki dalam konteks kota dapat berperan untuk menciptakan lingkungan manusiawi. Pejalan kaki adalah orang yang bergerak dalam satu ruang dengan berjalan kaki. Semua orang adalah pejalan kaki, bahkan pengendara kendaraan bermotor pun termasuk pejalan kaki untuk dapat berpindah dari kendaraan lainnya, untuk menuju ke tempat lain atau sebaliknya. Penelitian ini diharapkan memilik tujuan untuk mengetahui pola perilaku pejalan kaki di kawasan Kawasan Alun-alun Kota Lamongan dalam menggunakan jalur pedestrian untuk aktifitas.

\section{Pemetaan Perilaku}

Upaya mendapat gambaran perilaku pejalan kaki di ruang public adalah melalui pengamatan pada seseorang untuk mengetahui kemana orang tersebut pergi, bagaimana pergerakan mereka dengan pengukuran jejak fisik serta pemetaan perilaku (Sommer,1986). Teknik ini mempunyai kekuatan pada aspek 
spatialnya yaitu untuk mengetahui bentuk informasi fenomena perilaku individu atau sekelompok manusia yang terkait dengan sistem spasial.

Pemetaan perilaku (Behavioral Mapping) dilakukan dengan penggambaran bentuk sketsa atau diagram melalu area dimana manusia melakukan kegiatan untuk menggambarkan peilaku manusia pada suatu area dimana manusia malakukan kegiatan untuk menggambarkan perilaku manusia dalam peta, mengidentifikasi jenis dan frekuensi perilaku serta menunjukkan kaitan antar perilaku dengan rancangan yang spesifik.

Jenis perilaku yang dipetakan yaitu pola perjalanan melalui prosedur :

- Membuat sketsa area atau setting yang akan diobservasi

- Membuat definisi mengenai perilaku yang diamati, dihitung, maupun didiskripsikan

- Membuat rencana mengenai waktu pengamatan

\section{Personal Space}

Personal space menurut Fisher (dalam Sarwiono,1992 dalam Listianto 2006) merupakan batas atau konsep jarak yang tidak nampak disekeliling diri dan tidak boleh dilalui oleh orang lain. Konsep ini menimbulkan perilaku Crowding, secara umum dikatakan situasi seseorang tidak mampu mempertahankan personal spacenya disebabkan karena jumlah personal yang tinggi.

Terdapat empat macam jarak personal space (Sarwono,1992dalam Listianto 2006) :

1. Jarak intim $(0-0,5 \mathrm{~m})$

2. Jarak personal, jarak percakapan (1,5$3 \mathrm{~m})$

3. Jarak sosial, jarak untuk hubungan bersifat formal $(1,3-4 \mathrm{~m})$

4. Jarak publik $(4-8,5 \mathrm{~m})$

\section{Hubungan Manusia dengan Lingkungannya}

Menurut Colhoun (1995) dalam Listianto (2006), tentang penyesuaian dan hubunan kemanusiaan bahwa lingkungan dapat mempengaruhi perilaku. Lingkungan dapat menghalagi perilaku akibatnya juga membatasi apa yang diinginkan. Suatu lingkungan dapat menentuka seberapa jauh orangdapat berjalan di dalamnya.Lingkungan dapat mengundang atau mendatangkan perilaku, menentukan bagaimana manusia harus bertindak.
Lingkungan membatasi diri, perilaku yang membatasilingkungan dapat menjadi bagian tetap dari diri yang menentukan arah perkembangan kepribadian pada mana yangakan didatangi.

Kegiatan pejalan kaki dapat digolongkan menjadi berjalan, berdiri,duduk, berlari, berbaring, dan bermain, berjalan, berdiri dan duduk adalah kegiatan yang paling banyak dilakukan. Keenam kegiatan tersebut berdasarkan kepentingannya dapat dibagi menjadi tiga jenis kegiatan yaitu kegiatan utama, kegiatan pilihan dan kegiatan lanjutan. Kegiatan utama meliputi kegiatan berjalan untuk berbelanja, menunggu angkutan dan istirahat setelah berjalan lama. Kegiatan pilihan meliputi jalan-jalan santai, bersiri untuk melihat pemandangan. Kegiatan lanjutan adalah pejalan kaki berhenti dan duduk kemudian mereka dapat berbicara.

Terhadap lingkungan, manusia melakukan penyesuaian perilakunya. Perilaku ini ada dua jenis yaitu pejalan kaki merubah tingkahlaku agar sesuai dengan lingkungannya dan yang kedua adalah merubah lingkungan agar sesuai dengan tingkah laku. Perilaku sebagai prosesinteraksi antara pribadi individu ataupun kelompok dengan lingkungannya, sebab lingkungan mengandung rangsang yang dianggap manusia dalambentuk respon yang disebut perilaku (Wirawan, 1992 dalam Listianto 2006).

\section{METODE PENELITIAN}

\section{Tahap Penelitian}

Meliputi pembuatan proposal penelitian yang didahului dengan mengadakan survey untuk menjajagi fenomena yang terjadi yang diangkat sebagai masalah penelitian.

Tahap penelitian lapangan meliputi :

1. Observasi lapangan, pengamatan langsung (person centered mapping dan place centered mapping)

2. Pengambilan data primer (wawancara dengan kuisioner)

\section{Populasi dan Sampel Penelitian}

Dalam suatu penelitian, seringkali kita tidak dapat mengamati seluruh individu dalam suatu populasi. Hal ini dapat dikarenakan jumlah populasi yang amat besar, cakupan wilayah penelitian yang cukup luas, atau keterbatasan biaya penelitian. Untuk itu, 
kebanyakan penelitian menggunakan sampel. Sampel adalah bagian dari populasi yang digunakan untuk menyimpulkan atau menggambarkan populasi. Pemilihan sampel dengan metode yang tepat dapat menggambarkan kondisi populasi sesungguhnya yang akurat, dan dapat menghemat biaya penelitian secara efektif.
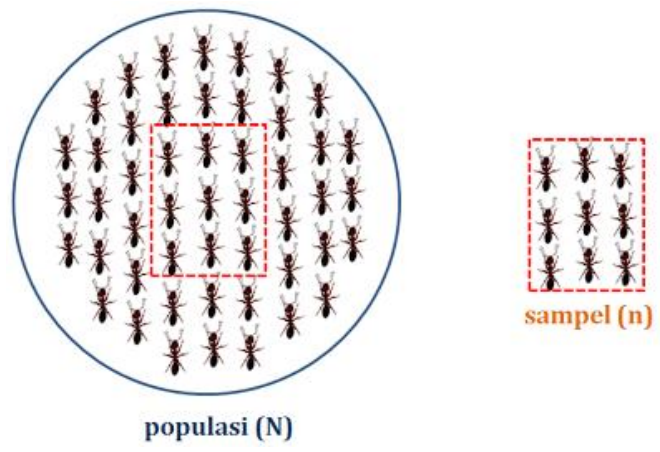

Gambar 1 Populasi dan Sampel

\section{Metode Slovin}

Pertanyaan dalam seringkali diajukan dalam metode pengambilan sampel adalah berapa jumlah sampel yang dibutuhkan dalam penelitian.Sampel yang terlalu kecil dapat menyebabkan penelitian tidak dapat menggambarkan kondisi populasi yang sesungguhnya. Sebaliknya, sampel yang terlalu besar dapat mengakibatkan pemborosan biaya penelitian.

Salah satu metode yang digunakan untuk menentukan jumlah sampel adalah menggunakan rumus Slovin (Sevilla et. al., 1960:182), sebagai berikut:

$$
n=\frac{N}{1+N e^{2}}
$$

dimana

$n$ : jumlah sampel

$\mathrm{N}$ : jumlah populasi

e: batas toleransi kesalahan (error tolerance)

Untuk menggunakan rumus ini, pertama ditentukan berapa batas toleransi kesalahan. Batas toleransi kesalahan ini dinyatakan dengan persentase. Semakin kecil toleransi kesalahan, semakin akurat sampel menggambarkan populasi. Misalnya, penelitian dengan batas kesalahan $5 \%$ berarti memiliki tingkat akurasi $95 \%$. Penelitian dengan batas kesalahan 2\% memiliki tingkat akurasi $98 \%$. Dengan jumlah populasi yang sama, semakin kecil toleransi kesalahan, semakin besar jumlah sampel yang dibutuhkan.

Pada penelitian ini, dilakukan pengamatan dan wawancara kepada petugas parkir maupun masyarakat sekitar tentang jumlah pengunjung yang mendatangi kawasan Alun-alun Kota Lamongan, wawancara ini dilakukan karena belum adanya jumlah pihak resmi yang dikeluarkan oleh pihak terkait.

Jumlah pengunjung pada:

1. Pada hari kerja senin-jumat berkisar antara 300 orang perhari

2. Pada hari sabtu dan minggu (kecuali pada jam car free day) berkisar antara 500 orang

Dari data tersebut didapatkan rata-rata pengunjung per harinya $(\mathbf{N})$ : 357 orang.

Kemudian dimasukkan ke dalam rumus slovin dengan toleransi kesalahan (e) $\mathbf{8 \%}$ maka di dapatkan

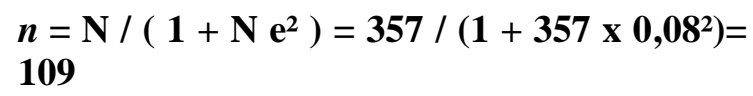

dengan demikian maka sampel (n) yang dibutuhkan untuk peneltian ini adalah $\mathbf{1 0 9}$ orang pengunjung.

\section{HASIL DAN PEMBAHASAN}

Tabel 1 Hasil kuisioner I

\begin{tabular}{clcc}
\hline No & \multicolumn{1}{c}{ Pertanyaan } & $\begin{array}{c}\text { Ya } \\
\%\end{array}$ & $\begin{array}{c}\text { Tidak } \\
\%\end{array}$ \\
\hline 1 & $\begin{array}{l}\text { Apakah saudara seringkali } \\
\text { berjalan di trotoar Alun- } \\
\text { alun Kota Lamongan? }\end{array}$ & 40 & 60 \\
\hline 2 & $\begin{array}{l}\text { Apakah saudara } \\
\text { mempunyai keinginan } \\
\text { untuk berjalan di trotoar } \\
\text { Alun-alun Kota } \\
\text { Lamongan? }\end{array}$ & 63 & 37 \\
\hline No & \multicolumn{1}{c}{ Pertanyaan } \\
& Ya & Tidak \\
\hline 3 & $\begin{array}{l}\text { Apakah saudara melewati } \\
\text { jalan di sekitar Alun-alun } \\
\text { Kota Lamongan untuk } \\
\text { kegiatan sehari-hari? }\end{array}$ & 45 & 55 \\
\hline 4 & $\begin{array}{l}\text { Apakah saudara sering } \\
\text { berkunjung untuk } \\
\text { menikmati keramaian } \\
\text { sekitar Alun-alun Kota } \\
\text { Lamongan? }\end{array}$ & 58 & 42 \\
\hline 5 & Apakah saudara & \\
\hline
\end{tabular}




\begin{tabular}{|c|c|c|c|}
\hline & $\begin{array}{l}\text { mengetahui maksud dari } \\
\text { jalur pedestrian (trotoar) } \\
\text { atau jalur pejalan kaki di } \\
\text { Alun-alun Kota } \\
\text { Lamongan? }\end{array}$ & & \\
\hline 6 & $\begin{array}{lr}\text { Apakah jalur pedestrian } \\
\text { (trotoar) di Alun-alun Kota } \\
\text { Lamongan } & \text { sudah } \\
\text { digunakan sesuai } & \text { dengan } \\
\text { fungsinya? } & \\
\end{array}$ & 40 & 60 \\
\hline 7 & $\begin{array}{l}\text { Apakah saudara nyaman } \\
\text { dalam menggunakan jalur } \\
\text { pedestrian (trotoar) di } \\
\text { Alun-alun Kota } \\
\text { Lamongan? }\end{array}$ & 60 & 40 \\
\hline 8 & $\begin{array}{l}\text { Apakah pedagang PKL } \\
\text { yang di jalur pedestrian } \\
\text { (trotoar) di Alun-alun Kota } \\
\text { Lamongan perlu dipindah? }\end{array}$ & 72 & 28 \\
\hline 9 & $\begin{array}{l}\text { Apakah seharusnya ada } \\
\text { tempat kusus PKL agar } \\
\text { tidak menggunakan jalur } \\
\text { pedestrian (trotoar) di } \\
\text { Alun-alun Kota } \\
\text { Lamongan? }\end{array}$ & 81 & 19 \\
\hline
\end{tabular}

Table 2 Apa yang membuat saudara mendatangi alun-alun?

\begin{tabular}{lc}
\hline \multicolumn{1}{c}{ Tanggapan } & $\begin{array}{c}\text { Frekuensi } \\
\mathbf{\%}\end{array}$ \\
\hline Bermain di Taman bermain & 24 \\
\hline Membeli Pedagang Kaki Lima & 8 \\
\hline Hanya duduk-duduk & 31 \\
\hline Lain-lain & 37 \\
\hline Jumlah & 100 \\
\hline
\end{tabular}

Table 3 Apa yang membuat anda tidak ingin berjalan di trotoar alun-alun kota Lamongan?

\begin{tabular}{lc}
\multicolumn{1}{c}{ Tanggapan } & $\begin{array}{c}\text { Frekuensi } \\
\text { \% }\end{array}$ \\
\hline Malas & 19 \\
\hline Lantai Licin & 15 \\
\hline Banyak pedagang di trotoar & 49 \\
\hline Lain-lain & 17 \\
\hline Jumlah & 100 \\
\hline
\end{tabular}

Table 4 Menurut anda apa yang kurang dari trotoar Alun-alun Kota Lamongan?

\begin{tabular}{lc}
\multicolumn{1}{c}{ Tanggapan } & $\begin{array}{c}\text { Frekuensi } \\
\mathbf{\%}\end{array}$ \\
\hline Tempat duduk & 31 \\
\hline Tempat Sampah & 33 \\
\hline Jalur untuk tuna netra & 8 \\
\hline Tidak ada & 13 \\
\hline Lain-lain & 16 \\
\hline Jumlah & 100 \\
\hline
\end{tabular}

Table 5 Menurut saudara apa kelebihan trotoar alun-alun kota Lamongan?

\begin{tabular}{lc}
\multicolumn{1}{c}{ Tanggapan } & $\begin{array}{c}\text { Frekuensi } \\
\text { \% }\end{array}$ \\
\hline Bersih & 19 \\
\hline Trotoar Lebar & 32 \\
\hline Motif keramiknya bagus & 10 \\
\hline Tidak ada & 37 \\
\hline Lain-lain & 3 \\
\hline Jumlah & 100 \\
\hline
\end{tabular}

Dari hasil kuisioner tersebut kita bisa tahu penilaian masyarakat bahwa trotoar yang sudah ada di Alun-alun Kota Lamongan tersebut masih nyaman bagi pengunjung, ada beberapa faktor yang mempengaruhi perilaku responden sebagai pengguna trotoar diantaranya peralihan fungsi trotoar sebagai tempat pedagang kaki lima yang menyebabkan responden tidak bisa berjalan di trotoar tersebut. Faktor penarik pengunjung pada kawasan Alun-alun Kota Lamongan ternyata adalah ruang terbuka yang menjadi ruang publik, karena masyarakat membutuhkan adanya tempat rekreasi yang dekat, murah, meriah. Tempat sampah beserta kursi taman adalah fasilitas yang paling diinginkan oleh responden untuk ditambahkan di trotoar terserbut.

\section{KESIMPULAN}

Hasil wawancara dan kuisioner yang telah dilakukan maka mayoritas koresponden menginginkan bahwa trotoar di Kawasan alunalun Kota Lamongan di kembalikan kepada 
fungsinya yaitu sebagai sarana dan prasarana pejalan kaki, karena saat ini trotoar tersebut beralih fungsi menjadi area ekonomi untuk lapak Pedagang Kaki Lima yang mulai berdagang pada sore hari sampai dengan malam hari.

Adanya Taman bermain sebagai ruang terbuka publik merupakan fasilitas yang dibutuhkan oleh masyarakat, perawatan secara berkala pada fasilitas yang sudah ada dan penambahan fasilitas-fasilitas pelengkap pada trotoar agar jalur pedestrian semakin nyaman dan aman untuk aktivitas pejalan kaki dan untuk menambah keindahan kota.

\section{DAFTAR PUSTAKA}

Anonim. 1999. Keputusan Direktur Jenderal Bina Marga No. 76/KPTS/Db/1999

Anonim. 2006. Permen PU Nomor: 30/PRT/M/2006

Arikunto, Suharsimi. 2002. Prosedur Penelitian suatu pendekatan praktek. Rineka Cipta. Jakarta

Lang, Jon. 1994. Creating Architecture Theory, The Role of the behavioral Science in Environmental Design, Van Nostrand Reinhold Company. New York.

Listianto, TerstiervyIndraPawaka. 2006. Hubungan Fungsi dan Kenyamanan Jalur Pedestrian, StudiKasus Jl. Pahlawan Semarang.Tesis Magister Teknik Universitas Diponegoro Semarang.

Lynch, Kevin. 1975. The Image of The City. Massachusetts Institute of Technology. USA

Rapoport, Amos. 1977. Human Aspect of Urban Form and Design. Perharmont Press. Indonesia

Rubeinstein, Harvey, M. 1992. Central City Malls.John Willey \& Sons. New York

Sarwono, Sarlita Wirawan. 1992. Psikologi Lingkungan. Universitas Indonesia. Jakarta

Sevilla, Consuelo G. et. al.2007. Research Methods. Rex Printing Company. Quezon City.

Shirvani, Hamid. 1985. The Urban Design Process. Van Nostrand Reinhold Company. New York.
Spreiregen, Paul D. 1986. Urban Architecture of Thown and Cities. McGraw Hill Book Company. New York. 
Halaman ini sengaja dikosongkan 